\title{
Real-time monitoring of indoor particulate matter concentration in a commercial broiler house
}

\author{
A. Peña Fernández ${ }^{1}$, T. G. M. Demmers ${ }^{2}$, Q. Tong $^{2}$, A. Youssef ${ }^{1}$, Tomas Norton ${ }^{1}$, D. \\ Berckmans $^{1}$
}

${ }^{1}$ Dept. of Biosystems, Animal and Human Health Engineering Division, M3-BIORES Lab., KU Leuven, Kasteelpark Arenberg 30, 3001 Heverlee, Belgium

${ }^{2}$ The Royal Veterinary College, Hawkshead Lane, North Mymms, Hatfield, AL9 7TA Hertfordshire, United Kingdom

\author{
Written for presentation at the \\ $1^{\text {th }}$ International Livestock Environment Symposium (ILES X) \\ Sponsored by ASABE \\ Omaha, Nebraska, USA
}

September 25-27, 2018

\begin{abstract}
Measuring indoor particulate matter concentration in poultry houses remains a difficult task. Aerosol analyzers are expensive and require frequent labor intensive maintenance. Precision Livestock Farming technologies support farmers in their daily routine of animal management, through monitoring animals continuously during their life in an automated, non-invasive way, without inducing additional stress in the animals. In this work, a model to relate broiler activity and ventilation rate with indoor particulate matter concentration has been developed.

For a complete growing cycle in a UK commercial broiler farm, broiler activity, using the eYeNamic ${ }^{\circledR}$ system, and ventilation rate, using the climate control system, were measured. Indoor concentration of different particulate matter sizes was continuously monitored using a DustTrak ${ }^{\circledR}$ analyzer. A Multi-Input Single-Output Transfer Function model was developed to monitor the impact of broiler activity and ventilation rate in the indoor particulate matter concentration. This model has an average accuracy of 74\%. A Dynamic Linear Regression model was developed to forecast indoor particulate matter concentration levels along every day of the growing cycle in real-time. This model achieved a Mean Relative Prediction Error of 2\%. This model has the potential to not only continuously estimate the aerosol concentration in the poultry house by automated monitoring of broiler activity and ventilation rate, but also to be part of a control system to manage aerosol concentration in the farm in real-time.
\end{abstract}

Keywords. Activity, dust, poultry, ventilation rate, precision livestock farming

\section{Introduction}

Chicken meat production is expected to reach 134 million metric tons in 2023 (OECD/FAO, 2014). Production of poultry meat is one of the higher producers of bio-aerosols, with estimates for $\mathrm{PM}_{10}$ and $\mathrm{PM}_{2.5}$ ranging from $40-57 \%$ and $45-50 \%$ of the total UK emission from housed livestock, respectively (Klimont and Amann, 2002). The most recent emission factors for PM2.5 and PM10 measured in the UK were 5.1 and $31.6 \mathrm{mg} \mathrm{animal}^{-1}$ day $^{-1}$ (Demmers et al, 2010). These values lie within the published range of values although, due to the difficulties and expenses of measurements, the amount of data available is low.

The authors are solely responsible for the content of this meeting presentation. The presentation does not necessarily reflect the official position of the American Society of Agricultural and Biological Engineers (ASABE), and its printing and distribution does not constitute an endorsement of views which may be expressed. Meeting presentations are not subject to the formal peer review process by ASABE editorial committees; therefore, they are not to be presented as refereed publications. Publish your paper in our journal after successfully completing the peer review process. See www.asabe.org/JournalSubmission for details. Citation of this work should state that it is from an ASABE meeting paper. EXAMPLE: Author's Last Name, Initials. 2018. Title of presentation. ASABE Paper No. ---. St. Joseph, MI.: ASABE. For information about securing permission to reprint or reproduce a meeting presentation, please contact ASABE at www.asabe.org/permissions (2950 Niles Road, St. Joseph, MI 49085-9659 USA). 
Poultry operations are obliged by law to demonstrate dust management measures. Normally, simple measures such as using pelleted rather than meal feed or end of pipe control are used. More complex systems are not commonly used and usually require an expensive and time consuming maintenance. Precision Livestock Farming (PLF) technology provides continuous measurement of variables on livestock farms through sensor data analysis, offering the potential to control their underlying process on-line (Wathes et al., 2008). It is expected that this technology can potentially link particulate matter concentration and animal activity and ventilation rate.

Dust concentration varies with animal activity (Demmers et al, 2011). In addition, ventilation rate impacts changes in particulate matter concentration (Calvet et al., 2010). In pig production, the variation of bio-aerosol concentration as function of several inputs, such as animal activity and ventilation rate has been tested using dynamic modelling (Aerts et al. 2008). In poultry production, there is still the need to develop such an approach.

Therefore, the aim of this work is to develop a model to relate indoor particulate matter concentration with broiler activity and ventilation rate measurements.

\section{Materials and Methods}

All measurements were carried out in a newly built mechanically ventilated broiler house $(110 \times 20 \mathrm{~m}$; capacity $55.000 \mathrm{birds}$ ) in the UK. The building was indirectly heated using a central heating system and heat exchangers placed below the ridgeline of the building. The complete growth cycle of the broilers was 36 days. The indoor particulate matter concentration was measured below two fan shafts using two DustTrak DRX analyzers (TSI Ltd.) fitted with a PM10 inlet, providing simultaneous data for PM1, PM2.5, PM5 and PM10 at 2 minute intervals. Ventilation rate was measured using three full size measuring fans (FANCOM B.V.) fitted below fans of ventilation stage 1, 2 and 3 (out of 6), as well as the duration each fan/stage was operational at any one time. The total flowrate calculated from these data was deemed to accurately measure the overall ventilation rate.

Broiler activity was measured using the eYeNamic ${ }^{\circledR}$ (FANCOM B.V.) system. It generates a visualization of the floor area and image analysis software translates the acquired images into activity indexes for every light period monitored. These indexes are a measure of animal movement. Data collection consists of two raw images per minute.

In order to evaluate the relation between particulate concentration and activity and ventilation rate, a Multi-Input SingleOutput (MISO) Transfer Function (TF) modelling approach was tested using MATLAB ${ }^{\circledR}$ (The Mathworks, Inc.) software and the CAPTAIN Toolbox (Taylor et al. 2007). The model has the following general structure (Young, 1984),

$$
y(k)=\sum \frac{B_{i}\left(z^{-1}\right)}{A\left(z^{-1}\right)} u_{i}\left(k-\delta_{i}\right)+\xi(k)
$$

where $y(k)$ and $u_{i}(k)$ are the output, particulate matter concentration, and the inputs of the model, broiler activity and ventilation rate; $\delta_{i}$ is the delay associated with the input $i ; \xi(k)$ is additive noise assumed to be zero mean, serially uncorrelated sequence of random variables with variance $\sigma^{2}$, accounting for measurement noise, modelling errors and effects of unmeasured inputs to the process; $k$ is the sample of the measurement; $A\left(z^{-1}\right)$ and $B_{i}\left(z^{-1}\right)$ are two series given by:

$$
\begin{aligned}
& A\left(z^{-1}\right)=1+a_{1} z^{-1}+a_{2} z^{-2}+\cdots+a_{n_{a}} z^{-n_{a}} \\
& B_{i}\left(z^{-1}\right)=b_{0}+b_{1} z^{-1}+b_{2} z^{-2}+\cdots+b_{n_{b}} z^{-n_{b}}
\end{aligned}
$$

where $a_{j}$ and $b_{j}$ are the model parameters to be estimated; $z^{-1}$ is the backward shift operator, $z^{-1} y(k)=y(k-1)$, with $y$ and $k$ defined as in Eq. (1) and $n_{a}$ and $n_{b_{i}}$ are the orders of the respective polynomials. The model parameters were estimated using a refined instrumental variable approach (Young, 1984). The model structure will be display as $\left[n_{a} n_{b_{1}} n_{b_{2}}\right.$ $\left.\begin{array}{lll}\delta_{l} & \delta_{2}\end{array}\right]$.

Following Aerts et al. (2003), a Dynamic Linear Regression modelling approach was also tested. In this study, on each discrete time instant $k$, the linear relation can be written as:

$$
D_{k}=c_{1, k}+c_{2, k} A c t v_{k}+c_{3, k} \operatorname{Vent}_{B, k}
$$

with $D$ the indoor particulate matter concentration $\left(\mathrm{mg} \cdot \mathrm{m}^{-3}\right), A_{c t v}$ the broiler activity index and Vent $_{k}$ the ventilation rate $\left(\mathrm{m}^{3} \cdot \mathrm{h}^{-1}\right)$ at time $k$, respectively. $c_{1, k}\left(\mathrm{mg} \cdot \mathrm{m}^{-3}\right)$ and $c_{2, k}\left(\mathrm{mg} \cdot \mathrm{m}^{-3}\right)$ and $c_{3, k}\left(\mathrm{mg} \cdot \mathrm{h} \cdot \mathrm{m}^{-6}\right)$ are the time-variant model parameters estimated at time $k$. The DLR goodness of the prediction estimations was quantified with the Mean Relative Prediction Error 
(MRPE), which is defined as:

$$
M R P E=\frac{1}{N} \sum_{k=1}^{N} \sqrt{\left(\frac{D_{k}-\widehat{D_{k}}}{D_{k}}\right)^{2}} \cdot 100
$$

where MRPE is a percentage; $N$ is the number of samples; $D k$ is the indoor particulate matter concentration measured at time $k\left(\mathrm{mg} \cdot \mathrm{m}^{-3}\right)$ and $\widehat{D_{k}}$ is the predicted concentration at time $k\left(\mathrm{mg} \cdot \mathrm{m}^{-3}\right)$ (Aerts et al., 2003).

\section{Results and Discussion}

In this preliminary study, the data gathered each day of a complete broiler growth cycle of 36 days was used. Firstly, the performance of a discrete-time MISO TF model was tested to evaluate the relation between the daily dynamics of indoor particulate matter concentration, broiler activity and ventilation rate. In Fig. 1, an example of broiler activity and ventilation

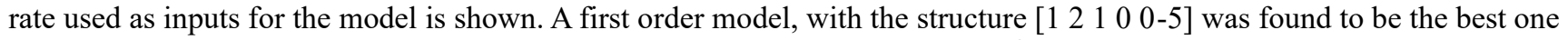
in terms of fitting agreement represented by the coefficient of determination $\left(R_{T}^{2}\right)$. On average, the fitting agreement along the growing cycle was $R_{T}^{2}=(74 \pm 12) \%$, with a maximum performance of $82 \%$ for specific days. The model structure obtained indicates that broiler activity accounts for the rapid variability in the particulate matter concentration while the ventilation rate accounts for the slow evolution of the indoor dust concentration within the day.
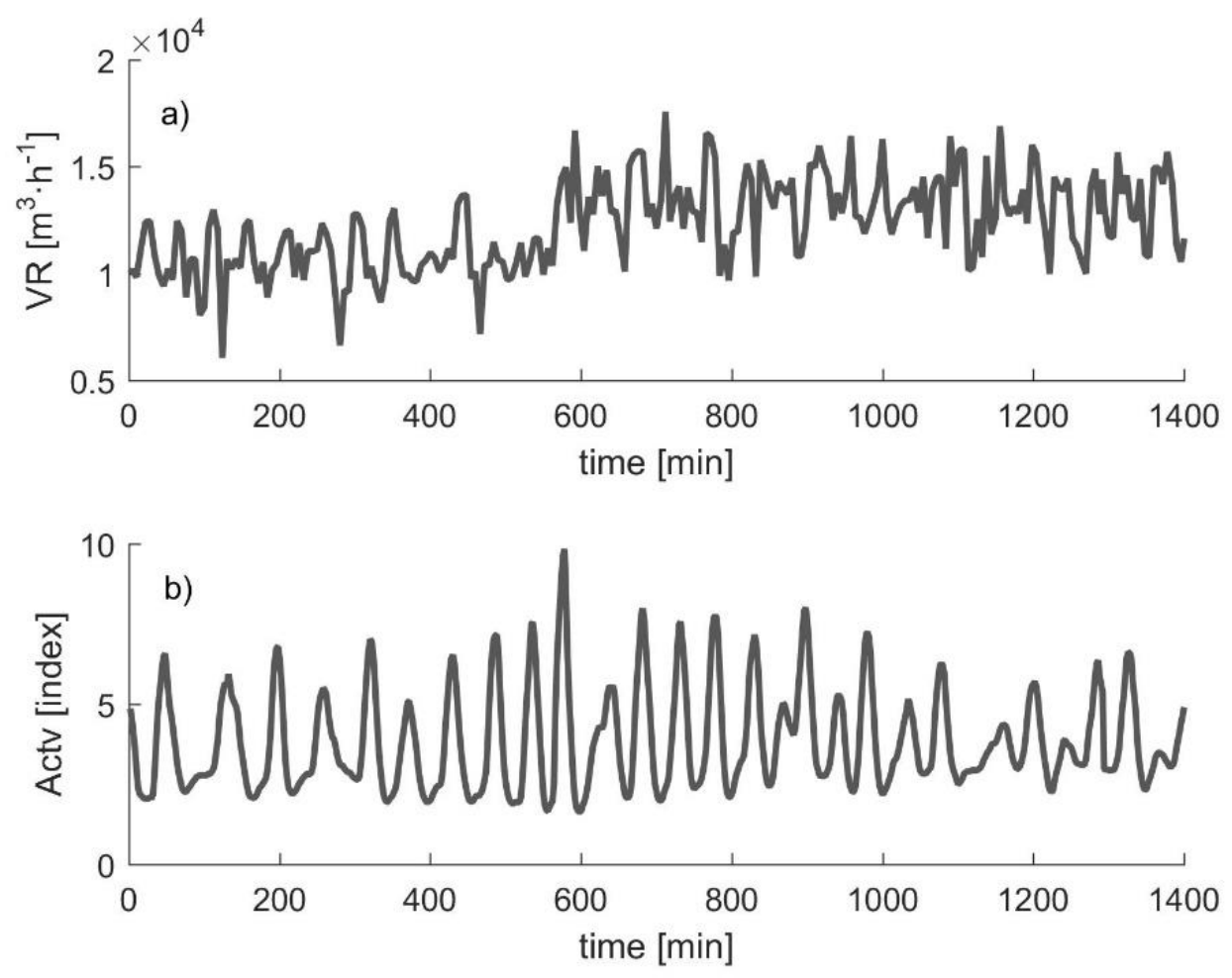

Figure 1: Ventilation rate (a) and activity level (b) datasets for a day in the growth cycle (day 10). These data were used in the system identification process to evaluate if it was possible to find a MISO TF model to relate them with the daily indoor dust concentration.

In Figure2, an example of the discrete-time MISO TF performance is shown. It can be seen that the general time evolution of the dust concentration within the day is captured by the model. The model performance fails in capturing the extreme values exhibited in the fast variation of the dust concentration. Therefore, improvements in the model are needed to account for this. However, this MISO TF model provides already a good estimation of the bio-aerosol concentration level inside the poultry house and its time evolution along the light period. 


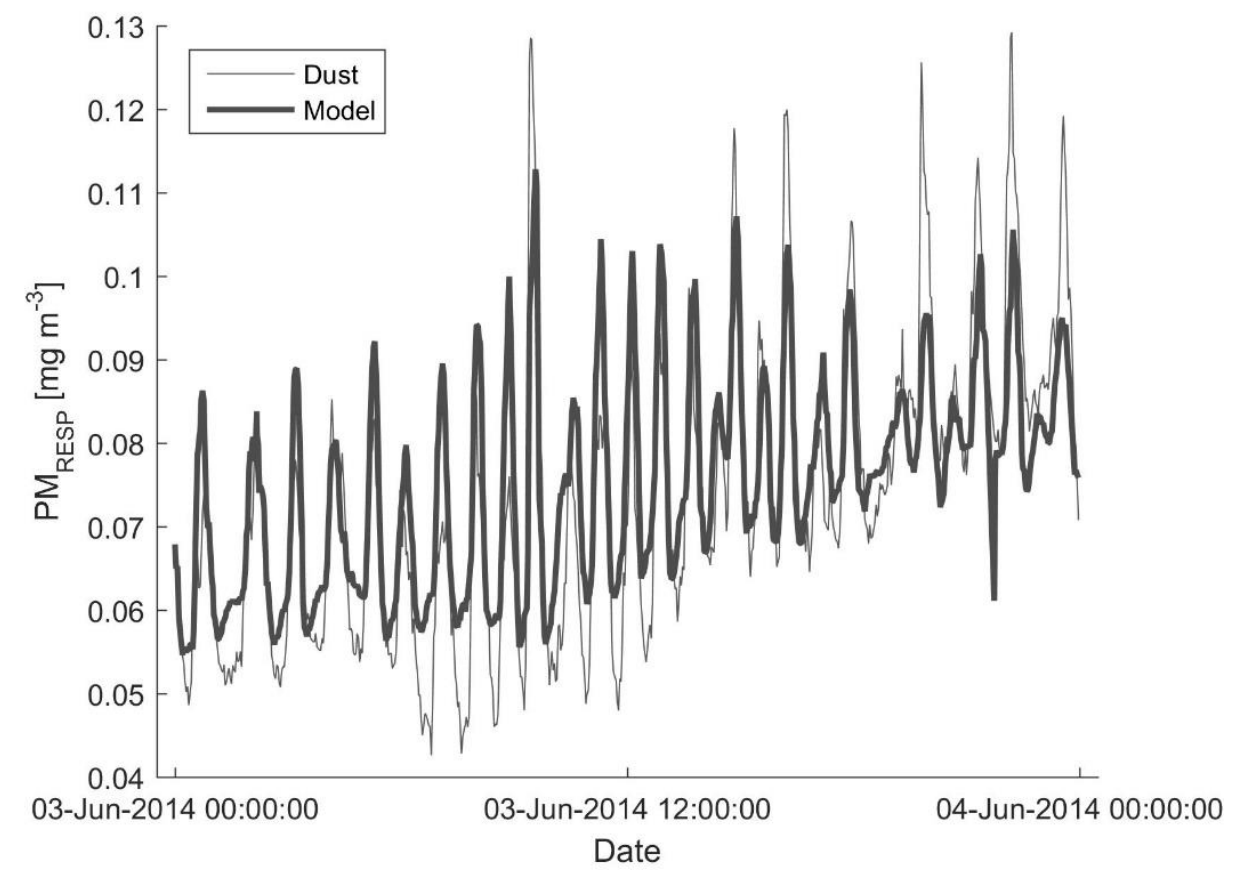

Figure 2: Example of the MISO TF model output (black), using broiler activity and ventilation rate as inputs, and respirable (RESP) particle size indoor particulate matter (PM) concentration (grey) as output for one day of the growing cycle (day 10).

In order to account for the extreme values, a DLR model is tested. The time-variant characteristics of its parameters are expected to deal with these extreme values from the fast daily variation. In Figure 3, an example of the comparison between the data gathered for the respirable particle size indoor particulate matter concentration and the DLR model output is displayed in graph a). In graph b), an example of the MRPE value in percentage for different combinations of window sizes ( 7 to $30 \mathrm{~min}$ ) and prediction horizons ( 1 to $7 \mathrm{~min}$ ) is displayed. It can be seen that the DLR model is able to capture all the dynamics exhibited by the indoor particulate matter concentration within a day of the growing cycle. From the 36 days of the growth cycle studied, the MRPE averaged $(1.8 \pm 0.2) \%$. Although these results should be taken as preliminary, it seems possible to monitor and predict indoor particulate matter concentration in a poultry house by means of a DLR model using broiler activity and ventilation rate as inputs. This model has the key features to become the core of a future control system to manage indoor particulate matter concentration.
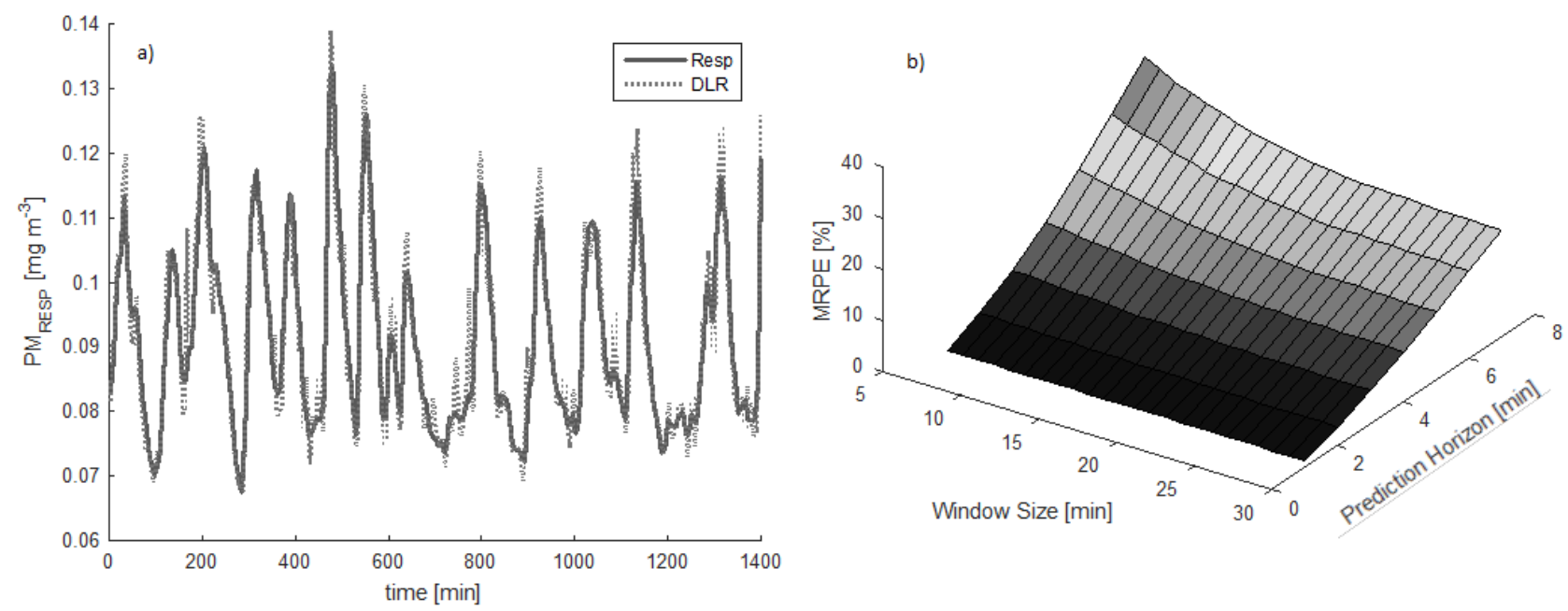

Figure 3. A Comparison between the respirable (RESP) particle size indoor particulate matter (PM) concentration data gather on day 1 of the growth cycle (solid) and the DLR model output using 14 min as window size (dashed) is displayed in graph (a). Graph (b) shows an example of the Mean Relative Prediction Error (MRPE), as percentage, for different combinations of time windows and prediction horizons when applying the DLR model to the datasets of day 1 in the growth cycle. 


\section{Conclusions}

In this study, broiler activity, ventilation rate and particulate matter concentration were monitored daily throughout the growth cycle. The potential of finding a discrete-time MISO TF model to relate the daily dust concentration dynamics with broiler activity and ventilation rate has been evaluated.

Firstly, a system identification process was used to find a discrete-time MISO TF model structure capable of relating broiler activity and ventilation with indoor particulate matter concentration within each day of the growth cycle. A first order model was found to show the best performance in terms of the fitting agreement, reaching an average performance of $R_{T}^{2}=$ $(74 \pm 12) \%$, with a performance up to $82 \%$ for specific days in the growing cycle. Next, a DLR model was tested in order to account for the extreme values of the daily variation. For a time window of 14 minutes, the average MRPE value taking into account the individual performance in each one of the growth cycle days is MRPE $=(1.8 \pm 0.2) \%$.

These results should be taken as preliminary because of the small sample data evaluated, just one growing cycle. Also, the performance in different particulate matter sizes should be evaluated. However, the model performance may allow development and testing of novel algorithms that might describe the relation between the total indoor particulate matter concentration and broiler activity and ventilation rate, with the goal to develop a control system to manage indoor particulate matter concentration in real-time.

\section{References}

Aerts, J., Lippens, M., De Groote, G., Buyse, J., Decuypere, E., Vranken, E., Berckmans, D. (2003). Recursive prediction of broiler growth response to feed intake by using a time-variant parameter estimation method. Poultr. Sci., 82 (1), 40-49.

Aerts, J. M., Vranken, E., Berckmans, D., \& Guarino, M. (2008). Modelling Dust Emission from Fattening Pig Houses. Automatika, 49(34), 119-125.

Calvet, S., Cambra-López, M., Blanes-Vidal, V., Estellés, F., \& Torres, A. G. (2010). Ventilation rates in mechanically-ventilated commercial poultry buildings in Southern Europe: Measurement system development and uncertainty analysis. Biosyst. Eng., 106(4), 423-432.

Demmers, T.G.M., Cao, Y., Parsons, D.J., Gauss, S., Lowe, J.C. \& Wathes C.M. (2011). Modelling and control of broiler activity, Proceedings of the XV ISAH Congress 2011 Viena, 243-246.

Demmers, T.G.M, Saponja, A., Thomas, R., Phillips, G., Mcdonald, A.,Stagg, S., Bowry, A., \& Nemitz, E. (2010). Dust and ammonia emissions from UK poultry houses. Proc. CIGR XVIIth World Congress June 13-17, 2010 Québec City, Canada, CSBE10942, 10pp

Klimont, Z. \& Amann, M. (2002). European control strategy for fine particles: the potential role of agriculture. Landbauforschung Völkenrode, Special issue 235, 29-35

OECD/FAO (2014). "Meat", in OECD-FAO Agricultural Outlook 2014, OECD Publishing.

Taylor, C. J., Pedregal, D. J., Young, P. C. \& Tych, W. (2007). Environmental Time Series Analysis and Forecasting with the Captain Toolbox. Environ. Modell. Software, 22, 797-814.

Wathes, C. M., Kristensen, H. H., Aerts, J. M., Berckmans, D. (2008). Is precision livestock farming an engineer's daydream or nightmare, an animal's friend or foe, and a farmer's panacea or pitfall? Comput. Electron. Agric., 64(1), 2-10.

Young P. C. (1984). Recursive Estimation and Time-series Analysis. Springer-Verlag, Berlin. 